\title{
A comparative study between the determination of dry matter digestibility in vitro and in vivo
}

M.de Figueiredo, A. Mbhele, J. Zondi and W. Majola

Dept of Agriculture, KwaZulu-Natal, Private bag X9059, Pietermaritzburg, 3200

\section{Introduction}

The digestibility value of a feed is one of the best indicators of nutritive value. In vivo determinations are expensive and time consuming rendering this technique impractical for routine analyses. In vitro determinations of digestibility using rumen fluid/cellulase have been used extensively in laboratories worldwide. The use of the Daisy II apparatus for the in vitro digestibility determination, using the Minson \& McLeod buffer and the $48 \mathrm{~h}$ pepsin digestion, was found to be easy and reliable. However, the difference in results between continuous shaking and twice daily shaking prompted a comparative study between in vivo and in vitro digestibility of kikuyu grass, ryegrass and eragrotis hay.

\section{Material and Methods}

Metabolic cages were used to house six sheep fed on kikuyu grass, ryegrass and eragrotis hay. The weight of the food given and left and of the faeces, was recorded daily for each sheep. The in vivo trials were conducted during a 10-day period using 10 Dohne wethers after a week of adaptation. A daily sample of the pasture given to each animal was analysed in vitro using the Daisy II apparatus and the procedure described by Minson \& McLeod with a $24 \mathrm{~h}$ pepsin digestion, with continuous and twice-daily shaking. The values of the samples analysed in vitro were compared with the values in vivo.

\section{Results and Discussion}

Results presented in Table 1, show that both eragrotis hay and ryegrass had a lower digestibility in vivo than in vitro with continuous shaking, but was higher when compared with in vitro with twice-daily shaking. Kikuyu grass, however, had a higher digestibility in vivo than in vitro with continuous shaking, rendering the comparison with in vitro with twice-daily shaking unnecessary.

Table 1 In vivo \& in vitro dry matter digestibility of eragrotis hay, ryegrass \& kikuyu grass

\begin{tabular}{lllc}
\hline & & In vitro Digestibility (\%) & \\
& In vivo Digestibility $(\%)$ & Continuous shaking & Twice-daily shaking \\
\hline Eragrotis hay & $62.36 \pm 1.795$ & $66.35 \pm 0.718$ & $31.00 \pm 1.417$ \\
Ryegrass & $82.84 \pm 2.491$ & $94.65 \pm 0.469$ & $88.41 \pm 1.073$ \\
Kikuyu grass & $80.73 \pm 4.57$ & $72.97 \pm 1.502$ & n.d. \\
\hline
\end{tabular}

The coefficient of variation (\%) within days and within sheep for the different trials is presented in Table 2 . The high coefficients of variation within days (between sheep) and between days (within sheep) for the in vivo values of the different feeds tested, explain the inability to develop a meaningful regression equation which would enable the prediction of in vivo results from the in vitro ones.

Table 2 Coefficient of variation (\%) of in vivo and in vitro dry matter digestibility within days and within sheep for the different trials.

\begin{tabular}{llclclc}
\hline & In vivo & & \multicolumn{2}{l}{ In vitro (continuous shaking) } & \multicolumn{2}{l}{ In vitro (twice daily shaking) } \\
& within days & within sheep & within days & within sheep & within days & between sheep \\
\cline { 2 - 7 } & 7.00 to 39.15 & 11.47 to 33.16 & 1.15 to 6.10 & 3.44 to 7.18 & 6.30 to 39.03 & 23.88 to 24.68 \\
$\begin{array}{l}\text { E. hay } \\
\text { Ryegrass }\end{array}$ & 1.81 to 18.06 & 7.51 to 13.50 & 0.31 to 1.48 & 1.22 to 1.60 & 1.01 to 2.21 & 2.72 to 3.39 \\
$\begin{array}{l}\text { Kikuyu } \\
\text { grass }\end{array}$ & 2.56 to 18.69 & 6.64 to 22.70 & 8.96 to 19.67 & 3.09 to 12.99 & n.d. & n.d. \\
\hline
\end{tabular}


(c) South African Society of Animal Science

Short paper and poster abstracts: $38^{\text {th }}$ Congress of the South African Society of Animal Science

\section{Conclusion}

The above study has shown that although the in vitro determination of dry matter digestibility values cannot be used as the absolute value of the feeds analysed, relative values when comparing different feeds are reproducible and are an accurate way of comparison.

\section{References}

Minson, D.J. \& McLeod, M.N., 1972. Division of Tropical Pastures Technical Paper No. 8, Commonwealth Scientific and Industrial Research Organization, Australia 